Classification

Physics Abstracts

$64.70 \mathrm{D}-68.55$

\title{
The melting of submonolayer ethane adsorbed on graphite : a LEED study
}

\author{
J. M. Gay, J. Suzanne and R. Wang (*) \\ Département de Physique (**), Faculté des Sciences de Luminy, Case 901, 13288 Marseille Cedex 9, \\ France
}

(Reçu le 28 décembre 1984, révisé le 6 mars 1985, accepté le 18 mars 1985)

\begin{abstract}
Résumé. - Nous avons étudié la fusion d'une sous-monocouche d'éthane adsorbée sur un monocristal de graphite par Diffraction d'Electrons Lents (DEL). La phase solide $S_{1}$ possède une maille rectangulaire commensurable $4 \times \sqrt{3}$ avec une structure moléculaire en chevrons. A $T=65 \mathrm{~K}, \mathrm{~S}_{1}$ se transforme en un liquide de réseau $I_{1}$ de symétrie hexagonale, commensurable $2 \times 2$. Lorsqu'on augmente la température, $I_{1}$ perd son ordre positionnel et d'orientation des liaisons de manière continue. A $95 \mathrm{~K}$, la figure de DEL est un anneau diffus, caractéristique d'un liquide isotrope.

Abstract. - The melting of ethane submonolayers has been studied by Low Energy Electron Diffraction (LEED). The solid phase $S_{1}$ has a $4 \times \sqrt{3}$ rectangular commensurate structure with a herring-bone packing. At $T=65 \mathrm{~K}, \mathrm{~S}_{1}$ melts into a lattice fluid $\mathrm{I}_{1}$ having the hexagonal symmetry of a $2 \times 2$ commensurate structure. With increasing $T, I_{1}$ continuously loses its positional and bond orientational orders. At $T=95 \mathrm{~K}$, the LEED pattern shows a diffuse ring, characteristic of an isotropic fluid.
\end{abstract}

Melting in two dimensions (2D) has attracted much attention since Kosterlitz and Thouless presented their theory of dislocation-mediated melting and suggested that this transition should be continuous [1]. Since then, theories [2-4], experiments [5-12] and computer simulations [13-15] have brought about a lot of controversial matter. For instance, Abraham [15], Migone et al. [10] and Hurlburt et al. [12] have shown that a seemingly continuous melting transition can be observed to be first order under careful investigation, using more appropriate techniques. However, recent $\mathrm{X}$-rays experiments, seemed to show a continuous melting into a hexatic phase for an incommensurate monolayer of xenon adsorbed on single crystals of exfoliated graphite [16. Melting transitions from commensurate phases have also been reported and are generally considered to be disordering transitions [17].

This Letter describes a LEED study of the melting of submonolayer ethane films adsorbed on graphite single crystals. This transition is particularly interesting for it occurs from a com-

(*) Present address : Department of Physics, University of Missouri-Columbia, Columbia, Mo 65211, USA.

(**) Unité associée au CNRS, no 794. 


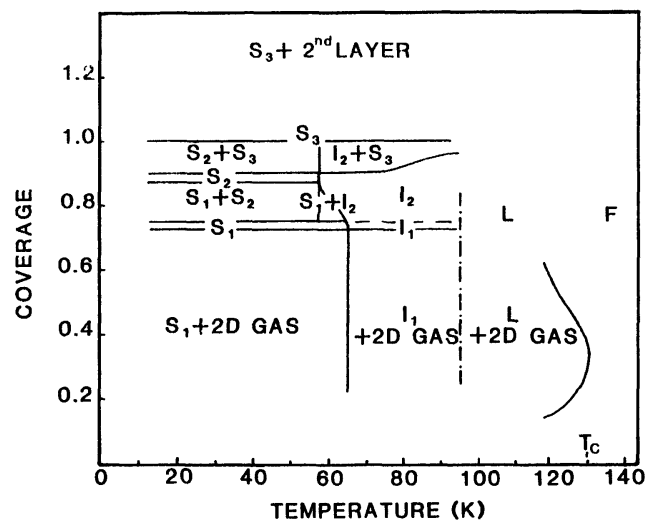

Fig. 1. - Tentative phase diagram of ethane monolayer adsorbed on graphite [34]. Coverage of one monolayer corresponds to that of the phase $S_{3}$. See table I for characteristics of the various $2 \mathrm{D}$ phases.

mensurate solid phase having a herring-bone structure. The system ethane/graphite has been studied previously by numerous techniques : classical volumetry [18], elastic [19-21] and inelastic [22] neutron scattering and LEED [23]. A more complete study of the structure and thermodynamics of ethane adsorbed on graphite has been performed and will be presented later [24]. It has allowed us to complete the 2D phase diagram of reference [23]. As shown in figure 1, it features three solids $S_{1}, S_{2}$ and $S_{3}$, two intermediate phases $I_{1}$ and $I_{2}$ and fluid phases $L$ and $F$. Table $I$

Table I.

\begin{tabular}{|c|l|c|c|}
\hline Phase & \multicolumn{1}{|c|}{ Structure } & Area/molecule & Temperature range \\
\hline $\mathrm{S}_{1}$ & $\begin{array}{l}\text { Rectangular } \\
\text { Commensurate } 4 \times \sqrt{3} \\
\text { Herring-bone packing } \\
\text { C-C } / / \text { surface }\end{array}$ & $\begin{array}{c}\text { 21 } \AA^{2} \\
(2 \text { molecules/cell })\end{array}$ & $T \lesssim 65 \mathrm{~K}$ \\
\hline $\mathrm{S}_{2}$ & $\begin{array}{l}\text { Rectangular } \\
\text { Commensurate } 10 \times 2 \sqrt{3} \\
\text { Packing unknown }\end{array}$ & $\begin{array}{l}17 \AA^{2} \\
\text { molecules/cell })\end{array}$ & $T \lesssim 57 \mathrm{~K}$ \\
\hline $\mathrm{S}_{3}$ & $\begin{array}{l}\text { Triangular } \\
\text { Commensurate } \sqrt{3} \times \sqrt{3} \\
\text { C-C } \perp \text { surface }\end{array}$ & $15.7 \AA^{2}$ & $T \lesssim 85 \mathrm{~K}$ \\
\hline $\mathrm{I}_{1}$ & $\begin{array}{l}\text { Triangular } \\
\text { Commensurate } 2 \times 2 \\
\text { Close-packed }\end{array}$ & $21 \AA^{2}$ & $T \lesssim 90 \mathrm{~K}$ \\
\hline $\mathrm{I}_{2}$ & $\begin{array}{l}\text { Triangular } \\
\text { Incommensurate } \\
\text { Close-packed }\end{array}$ & $21 \AA^{2}<a<16.5 \AA^{2}$ & $T<90 \mathrm{~K}$ \\
\hline
\end{tabular}


presents the characteristics of the various $2 \mathrm{D}$ phases. In the present work, we have studied the sequence of phases $S_{1} \rightarrow I_{1} \rightarrow L$ in more details and tried to determine the nature of the intermediate phase $I_{1}$.

The domains of stability of the different 2D phases being known, we can set the conditions of substrate temperature and pressure of $3 \mathrm{D}$ ethane gas in the chamber in order to have a pure $\mathrm{I}_{1}$ or L phase (coverage 0.7 on the phase diagram of Fig. 1).

The study has been made from photographs and negatives employing ILFORD HP5 film (400 ASA) taken with $35 \mathrm{~mm}$ Nikon camera and an exposure time of $30 \mathrm{~s}$. We have used a computer controlled photodensitometer to measure the spot intensity. The response of the film has been supposed linear. A more careful analysis would take account of the film response versus intensity. A calibration will be made in the future but would probably not change the qualitative features of the present results.

We have first studied the $S_{1} \rightarrow I_{1}$ transition. In previous works [19, 23], it has been tentatively interpreted as being a transition to an orientationally disordered solid. As pointed out in reference [23], this transition is somewhat analogous to the orientational order-disorder transition observed at $27 \mathrm{~K}$ for nitrogen adsorbed on graphite $[25,26]$. As for nitrogen, the densities of $S_{1}$ and $I_{1}$ are equal (Table I). However, the analogy is limited : in the case of ethane, the molecules no longer remain in their original sites $\left(S_{1}: 4 \times \sqrt{3} \rightarrow I_{1}: 2 \times 2\right)$. Furthermore $I_{1}$ has a shorter positional order correlation length $L$ than $S_{1}$. Measurements on LEED patterns show that $L \simeq 50 \AA$ for $\mathrm{I}_{1}$ close to the $\mathrm{S}_{1} \rightarrow \mathrm{I}_{1}$ transition $(70 \mathrm{~K})$, in agreement with previous neutron diffraction experiments [21] which give also $L=120 \AA$ for $S_{1}$.

We think at the present time that unlike the commensurate disordered phase of $\mathrm{N}_{2} /$ graphite, $I_{1}$ is a lattice fluid. According to this picture, molecules are translating and rotating, but on average, their centres of mass spend most of the time on $2 \times 2$ sites. To argue for the lattice fluid model, we have considered recent results on the measurements of the mobility of ethane molecules in the $I_{1}$ phase by quasi-elastic neutron scattering (QENS) [27]. They show translational diffusion above $65 \mathrm{~K}$ and an increase of mobility with temperature. Furthermore, NMR experiments have shown an increase of mobility above $65 \mathrm{~K}$ [28]. It is also worth noticing that the value of the ratio

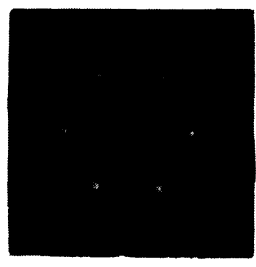

a. $\mathrm{T}=70 \mathrm{~K}$

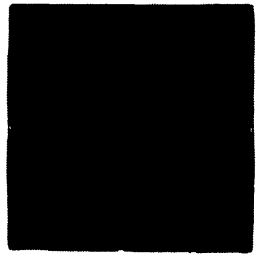

e. $T=90.7 \mathrm{~K}$

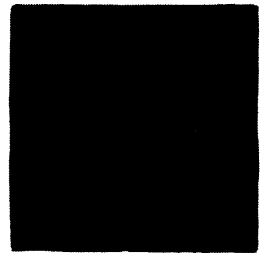

b. $T=74 \mathrm{~K}$

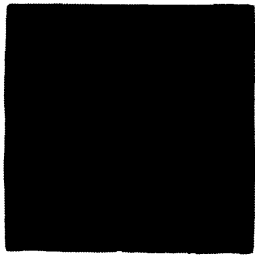

f. $T=95.5 \mathrm{~K}$

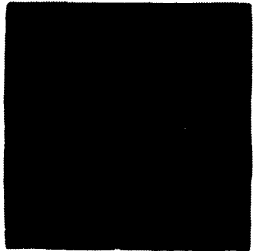

c. $\mathrm{T}=82.5 \mathrm{~K}$

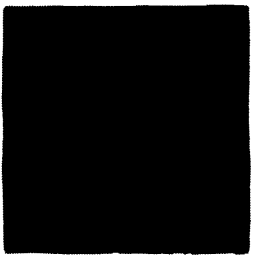

g. $T=100 \mathrm{~K}$

Fig. 2. - LEED patterns of ethane submonolayer adsorbed on graphite showing the continuous change in the positional and bond orientational orders of the lattice fluid $\mathrm{I}_{1}$. Figure $2 \mathrm{a}$ shows a rather well correlated $2 \times 2$ commensurate phase. At $95.5 \mathrm{~K}$, figure $2 \mathrm{f}$, the spots have merged into a broad, diffuse ring, and the fluid phase is no longer commensurate (distance between molecules in the $2 \times 2$ phase : $4.92 \AA$ ). 


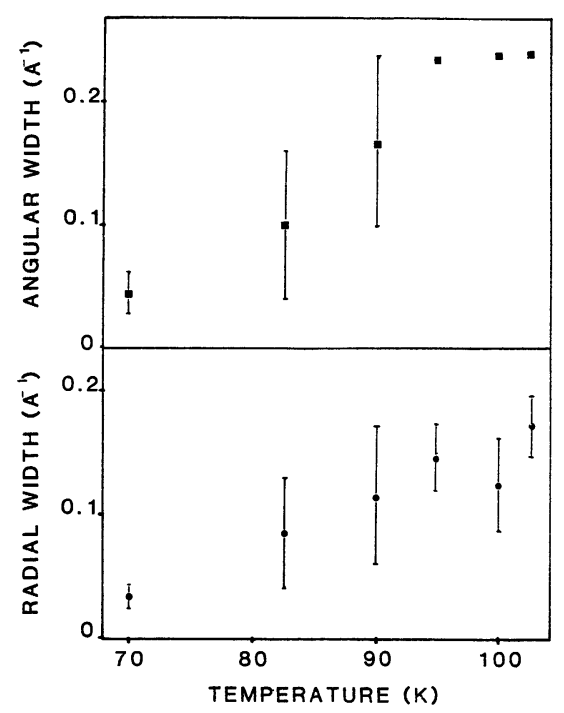

Fig. 3. - Angular and radial widths of the $I_{1}$ spot versus temperature. The widths increase continuously with $T$. Above $95 \mathrm{~K}$, the angular width is constant which means that the pattern is ring-like.

of the temperature of the $\mathrm{S}_{1} \rightarrow \mathrm{I}_{1}$ transition to that of the $3 \mathrm{D}$ triple point $T\left(\mathrm{~S}_{1} \rightarrow \mathrm{I}_{1}\right) / T_{t}(3 \mathrm{D})=$ 0.72 is very close to the ratio of the temperature of melting to the $3 \mathrm{D}$ triple point $T_{\mathrm{M}}(2 \mathrm{D}) / T_{\mathrm{t}}(3 \mathrm{D})$ of commensurate krypton (0.73) [29] or nitrogen (0.75) [30]. As expected, it is larger than the same ratio for various incommensurate adsorbates on graphite (0.62 for $\mathrm{Xe}$ [31] and $\mathrm{CH}_{4}$ [32]). This is another argument in favour of the fluid like nature of $I_{1}$ if we admit that the barrier to translational motion for ethane molecules rotating above the surface is of the same order of magnitude as the rare gases or $\mathrm{CH}_{4}$. The lattice fluid model also explains the lack of long range order observed for $\mathrm{I}_{1}$.

We have also studied the $I_{1}$ lattice fluid with increasing $T$. Figure 2 shows a series of LEED patterns at different $T$. As said before, they correspond to the pure $\mathrm{I}_{1}$ phase and then pure $\mathrm{L}$ phase. Close to the $S_{1} \rightarrow I_{1}$ transition $(T=70 \mathrm{~K})$, the $2 \times 2$ triangular commensurate structure is observed. At higher $T$, the spots elongate angularly and give gradually a ring like pattern observable at $T \geqslant 95 \mathrm{~K}$. At the same time, the fluid becomes incommensurate expanded (4.45 $\AA$, i.e. $+4 \%$, at $T=100 \mathrm{~K}$ ). Figure 3 shows the variation of the radial and angular widths of the spots versus temperature. It can be seen that the angular and radial widths change continuously with increasing $T$. Unlike for xenon and the interpretation of the results published in reference [16], we think that the bond orientational order of ethane on the graphite surface is due to the substrate field. When $T$ increases, the residence time in $2 \times 2$ sites decreases, reducing the range of order in the fluid. This shorter residence time is confirmed by the increase of translational mobility with $T$ shown by QENS [27]. It is interesting to notice that the parameter increases, i.e. is no longer that of the $2 \times 2$ structure when the bond orientational order is lost. Hence the $I_{1}$ lattice fluid loses its $2 \times 2$ modulation and becomes an isotropic fluid at a disorder line located around $95 \mathrm{~K}$ as shown in figure 1 (vertical dash-dotted line).

As a conclusion, the melting of the $S_{1}$ phase of ethane submonolayer occurs via an intermediate phase $I_{1}$ which is a lattice fluid having the $2 \times 2$ modulation. The $S_{1} \rightarrow I_{1}$ transition occurs at $65 \mathrm{~K}$. An increase of temperature decreases the positional and bond-orientational orders of the lattice fluid in a continuous manner. Above $95 \mathrm{~K}$, the fluid loses its $2 \times 2$ modulation and becomes isotropic. Finally, we cannot definitively rule out the existence of a plastic phase between the solid $S_{1}$ and the lattice fluid $I_{1}$ in a very narrow temperature range. Let us recall that a plastic phase exists for 3D ethane between $89.9 \mathrm{~K}$ and $90.3 \mathrm{~K}$ [33]. 


\section{Acknowledgments.}

We are grateful to M. Bienfait and J. P. Coulomb for the communication of their QENS results and R. Rollefson for the communication of his NMR data prior to publication. We also thank J. G. Dash and M. Schick for their comments. One of us (R.W.) thanks N.S.F. for financial assistance through the U.S.-France scientific program.

\section{References}

[1] Kosterlitz, J. M., Thouless, D. J., J. Phys. C 6 (1973) 1181.

[2] Nelson, D. R., Halperin, B. I., Phys. Rev. B 19 (1979) 2457.

[3] Young, A. P., Phys. Rev. B 19 (1979) 1855.

[4] Chui, S. T., Phys. Rev. Lett. 48 (1982) 933 ; Phys. Rev. B 28 (1983) 178.

[5] Taub, H., Carneiro, K., KJems, J. K., Passell, L., McTague, J. P., Phys. Rev. B 16 (1977) 4551.

[6] Chung, T. T., Surface Sci. 87 (1979) 348.

[7] Coulomb, J. P., Suzanne, J., Bienfait, M., Matecki, M., Thomy, A., Croset, B., Marti, C., J. Physique 41 (1980) 1155.

[8] Heiney, P. A., Birgeneau, R. J., Brown, G. S., Horn, P. M., Moncton, D. E., Stephens, P. W., Phys. Rev. Lett. 48 (1982) 104.

[9] McTague, J. P., Als-Nielsen, J., Bohr, J., Nielsen, M., Phys. Rev. B 25 (1982) 7765.

[10] Migone, A. D., Li, Z. R., Chan, M. H. W., Phys. Rev. Lett. 53 (1984) 810.

[11] Dimon, P., Horn, P. M., Sutton, M., Birgeneau, R. J., Moncton, D. E., to be published.

[12] Hurlburt, S. B., Dash, J. G., to be published.

[13] Frenkel, D., McTague, J. P., Phys. Rev. Lett. 42 (1979) 1632.

[14] Abraham, F. F., Phys. Rev. Lett. 44 (1980) 463 ; Phys. Rev. Lett. 50 (1983) 978 ; Phys. Rev. B 28 (1983) 7338.

[15] Abraham, F. F., Phys. Rev. B 29 (1984) 2606.

[16] Rosenbaum, T. F., Nagler, S. E., Horn, P. M., Phys. Rev. Lett. 50 (1983) 1791.

[17] HuSE, D. A., Phys. Rev. B 29 (1984) 5031.

[18] Regnier, J., Menaucourt, J., Thomy, A., Duval, X., J. Chim. Phys. 78 (1981) 629.

[19] Coulomb, J. P., Biberian, J. P., Suzanne, J., Thomy, A., Trott, G. J., Taub, H., Danner, H. R., HANSEN, F. Y., Phys. Rev. Lett. 43 (1979) 1878.

[20] Taub, H., Trott, G. J., Hansen, F. Y., Danner, H. R., Coulomb, J. P., Biberian, J. P., Suzanne, J., Tному, A., in S. K. Sinha, Ed., Ordering in two dimensions (North Holland, New York) 1980, p. 91.

[21] Trott, G. J., Ph. D. Thesis, University of Missouri-Columbia, 1981.

[22] Hansen, F. Y., Wang, R., Taub, H., Shechter, R., Reichel, D. G., Danner, H. R., Alldredge, G. P., Phys. Rev. Lett. 53 (1984) 572.

[23] Suzanne, J., Seguin, J. L., Taub, H., Biberian, J. P., Surface Sci. 125 (1983) 153.

[24] GaY, J. M., SuZANne, J., Wang, R., to be published.

[25] Diehl, R. D., Toney, M. F., Fain, S. C. Jr., Phys. Rev. Lett. 48 (1982) 177.

[26] DieHL, R. D., FaIN, S. C. Jr., Surface Sci. 125 (1983) 116.

[27] Measurements have been performed showing an increase of mobility of $\mathrm{C}_{2} \mathrm{H}_{6}$ molecules above $65 \mathrm{~K}$. The results are currently analysed in more details (COULOMB, J. P., BIENFAIT, M., to be published).

[28] Rollefson, R. et al., to be published.

[29] LARHER, Y., J. Chem. Soc. Faraday Trans. I 70 (1974) 320.

[30] Diehl, R. D., Fain, S. C., J. Chem. Phys. 77 (1982) 5065.

[31] Thомy, A., Duval, X., J. Chim. Phys. 67 (1970) 1101.

[32] Glachant, A., Coulomb, J. P., Bienfait, M., J. Physique Lett. 40 (1979) L-543.

[33] Van Nees, G. H. J., Vos, A., Acta Cryst. B 34 (1978) 1947.

[34] The region around $T_{\mathrm{c}}$ is taken from Ref. [18]. This phase diagram is discussed in more details in a following paper (GAY, J. M., SuZANNE, J., WANG, R., to be published). 